\title{
Power improvement of finned solar photovoltaic phase change \\ material system
}

\author{
Preeti Singh $^{\mathrm{a}, 1}$, Sourav Khanna ${ }^{\mathrm{b}, 1, *}$, Victor Becerra ${ }^{\mathrm{b}}$, Sanjeev Newar ${ }^{\mathrm{a}}$, Vashi Sharma ${ }^{\mathrm{a}}$, \\ Tapas K. Mallick ${ }^{\mathrm{c}}$, David Hutchinson ${ }^{\mathrm{d}}$, Jovana Radulovic ${ }^{\mathrm{e}}$, Rinat Khusainov ${ }^{\mathrm{f}}$ \\ a Indian Institute of Technology Kanpur, Kanpur 208016, India \\ ${ }^{\mathrm{b}}$ University of Portsmouth, School of Energy and Electronic Engineering, Portsmouth, UK \\ ${ }^{c}$ University of Exeter, Cornwall TR10 9FE UK \\ ${ }^{\mathrm{d}}$ University of Portsmouth, Faculty of Technology, Portsmouth, UK \\ ${ }^{\mathrm{e}}$ University of Portsmouth, School of Mechanical and Design Engineering, Portsmouth, UK \\ ${ }^{\mathrm{f}}$ University of Portsmouth, School of Computing, Portsmouth, UK
}

\begin{abstract}
Fins enabled Phase Change Material (FPCM) has potential to take away the thermal energy from photovoltaic (PV) and increase the efficiency. This study analyses the PVFPCM arrangement and presents a mathematical model. The arrangement is studied under various azimuths of wind, its flow rates, temperature of surroundings, phase change temperature and dimensions of FPCM confinement. The duration of power improvement of PV using FPCM, power production, efficiency improvement and Power-Voltage (P-V) curves are reported. The outcomes convey that as azimuth of wind changes from $75^{\circ}$ to $0^{\circ}$, the duration of power improvement elevates from $6.1 \mathrm{~h}$ to $7.3 \mathrm{~h}$ for $5 \mathrm{~cm}$ deep FPCM confinement. It increases from $4.9 \mathrm{~h}$ to $5.8 \mathrm{~h}$ for $4 \mathrm{~cm}$ deep FPCM confinement. Moreover, decrement in wind flow rate from $6 \mathrm{~m} / \mathrm{s}$ to $1 \mathrm{~m} / \mathrm{s}$ contracts the duration of power improvement from $7.8 \mathrm{~h}$ to $6.1 \mathrm{~h}$.
\end{abstract}

\footnotetext{
${ }^{1}$ First Author

* Corresponding Author: Email: sourav.khanna1@gmail.com
} 


\section{Terminology}

\begin{tabular}{|c|c|}
\hline$C_{p}$ & heat capacity $\left(\mathrm{J} \mathrm{kg}^{-1} \mathrm{~K}^{-1}\right)$ \\
\hline$d_{c}$ & depth of confinement $(\mathrm{m})$ \\
\hline$d_{f}$ & fin's depth (m) \\
\hline$d_{s i}$ & silicon-layer depth (m) \\
\hline$F$ & shape factor \\
\hline$f$ & section of PCM in non-solid condition \\
\hline$F_{x}$ & volumetric push along the length $\left(\mathrm{N} \mathrm{m}^{-3}\right)$ \\
\hline$f_{w}$ & flow rate of wind $\left(\mathrm{m} \mathrm{s}^{-1}\right)$ \\
\hline$H_{f}$ & storage capacity in latent form $\left(\mathrm{J} \mathrm{kg}^{-1}\right)$ \\
\hline$L$ & confinement's length (m) \\
\hline$p$ & pressure $(\mathrm{Pa})$ \\
\hline$p_{f}$ & pitch of fins (m) \\
\hline$S$ & irradiance at top $\left(\mathrm{W} \mathrm{m}^{-2}\right)$ \\
\hline$T_{m}$ & phase change point $(\mathrm{K})$ \\
\hline$v$ & velocity $\left(\mathrm{m} \mathrm{s}^{-1}\right)$ \\
\hline$w_{f}$ & fins width (m) \\
\hline
\end{tabular}

\section{Greek Letters}

$\alpha$

absorptance

$\varepsilon$

thermal emittance

$\mu$

viscosity $\left(\mathrm{kg} \mathrm{m}^{-1} \mathrm{~s}^{-1}\right)$

$\rho$

density $\left(\mathrm{kg} \mathrm{m}^{-3}\right)$

$v$

viscosity $\left(\mathrm{m}^{2} / \mathrm{s}\right)$

$\tau$

transmittance 


\section{Introduction}

Thermal regulation of photovoltaic during operation is necessary for power improvement. Phase changing material has potential to take away the waste energy from the PV as shown below.

\subsection{Experimental Studies}

The photovoltaic panel with phase change material $\left(\mathrm{C}_{2 n} \mathrm{H}_{4 n+2} \mathrm{O}_{\mathrm{n}+1}\right)$ has been tested and $8 \%$ improvement in power is achieved under $800 \mathrm{~W} / \mathrm{m}^{2}$ of solar radiation by Baygi and Sadrameli [1]. The consequence of hot and cold environments on the usability of $\mathrm{CaCl}_{2} \mathrm{H}_{12} \mathrm{O}_{6}$ for photovoltaic has been tested by Hasan et al. [2] and the achieved improvements in power are $13.0 \%$ and $5.1 \%$ respectively. The immersion of fins in the phase change material (Rubitherm 25) for the photovoltaic cooling has been tested by Huang et al. [3] and 6\% improvement in power is achieved. The influence of roof-PV-PCM against the stand-PV-PCM has also been tested and the achieved improvements in power are $21 \%$ and $7 \%$ respectively [4]. Diverse categories of phase change material have also been tested for the photovoltaic [5] and the eutectic mixture of capric-palmitic acid is declared to be preferable. Kamkari et al. [6] have tested the consequence of inclination of confinement containing phase change material exposing back to heat-source and reported that the zero inclination can lead to early melting. A low-concentration photovoltaic has been enabled with phase change material (Rubitherm 42) by Sharma et al. [7] and the achieved improvement in power is $7.7 \%$. Nanomaterial enhanced phase change material has been tested for the photovoltaic thermal regulation by Waeli et al. [8]. A high-concentration photovoltaic has been enabled with phase change material (Paraffin-wax 50) by Su et al. [9] and the achieved improvement in power is $10.0 \%$. A combination of heat exchanger and phase change material (Rubitherm 30) has been enabled 
with photovoltaic by Hossain et al. [10]. Similar combination of heat exchanger and phase changing material has also been experimented by Maatallah et al. [11].

\subsection{Computational Studies}

Brano et al. [12] and Ciulla et al. [13] concurrently solved the equations of spatial and transient behaviour of phase change material (Rubitherm 27) enabled photovoltaic. The experimentation has attested the reliability of equations as the outcomes match with 93\% accuracy. Only diffusion equations have been solved in comparison of diffusion-convection combined equations for Rubitherm 35 enabled photovoltaic by Kant et al. [14] and the documented inaccuracy of former case is $6.4 \%$. A variety of phase change materials (Rubitherm 20, Rubitherm 25 and Rubitherm 28) have been considered by Kibria et al. [15] and the earliest melting is documented for the case of Rubitherm 20. During phase change [16], appropriate equations are documented by Biwole et al. [17]. Park et al. [18] have documented the best phase change temperature for optimal operation. Phase change material infusion with high conductive material is used by Atkin and Farid [19] and a boost of 7\% in power is documented. The immersion of fins in the phase change material (Rubitherm 25) for the photovoltaic cooling has been tested by Huang et al. [20] and an improvement of $3^{\circ} \mathrm{C}$ is achieved. Fins like structures inside the PCM are also discussed by Emam et al. [21] and reported that the perpendicular structures are influential. 
This study analyses the PV-FPCM system under various azimuths of wind, its flow rates, temperature of surroundings, phase change temperature and dimensions of FPCM confinement. In addition, the study presents a mathematical model to analyse the PV-FPCM system. The improvement in power production, improvement in efficiency, Power-Voltage curves and the duration of power improvement have been reported.

\section{Physical Model}

Current study involves the following arrangements: PV and PV-FPCM (Fig. 1) and investigates the inclined arrangements having an inclination angle of $\beta$. Length and depth of FPCM confinement are represented by $L$ and $d_{c}$ respectively. Width, depth and pitch of fins are represented by $w_{f}, d_{f}$ and $p_{f}$ respectively.

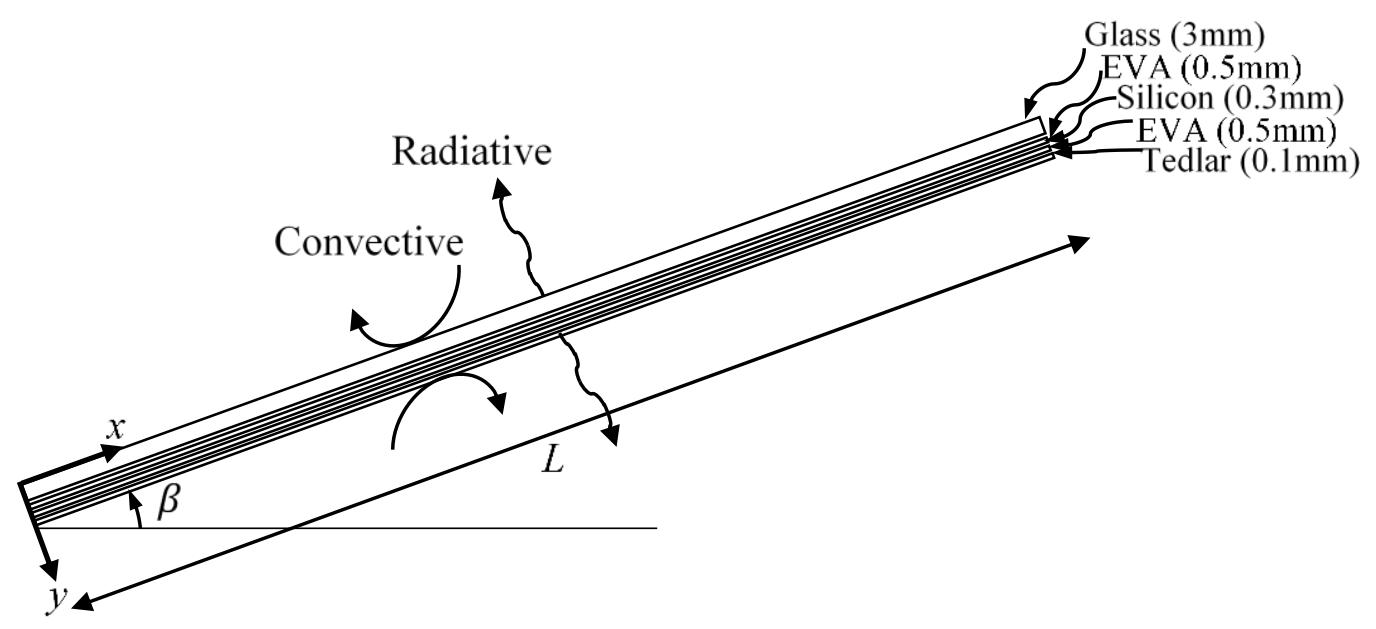

(a) PV-alone arrangement 


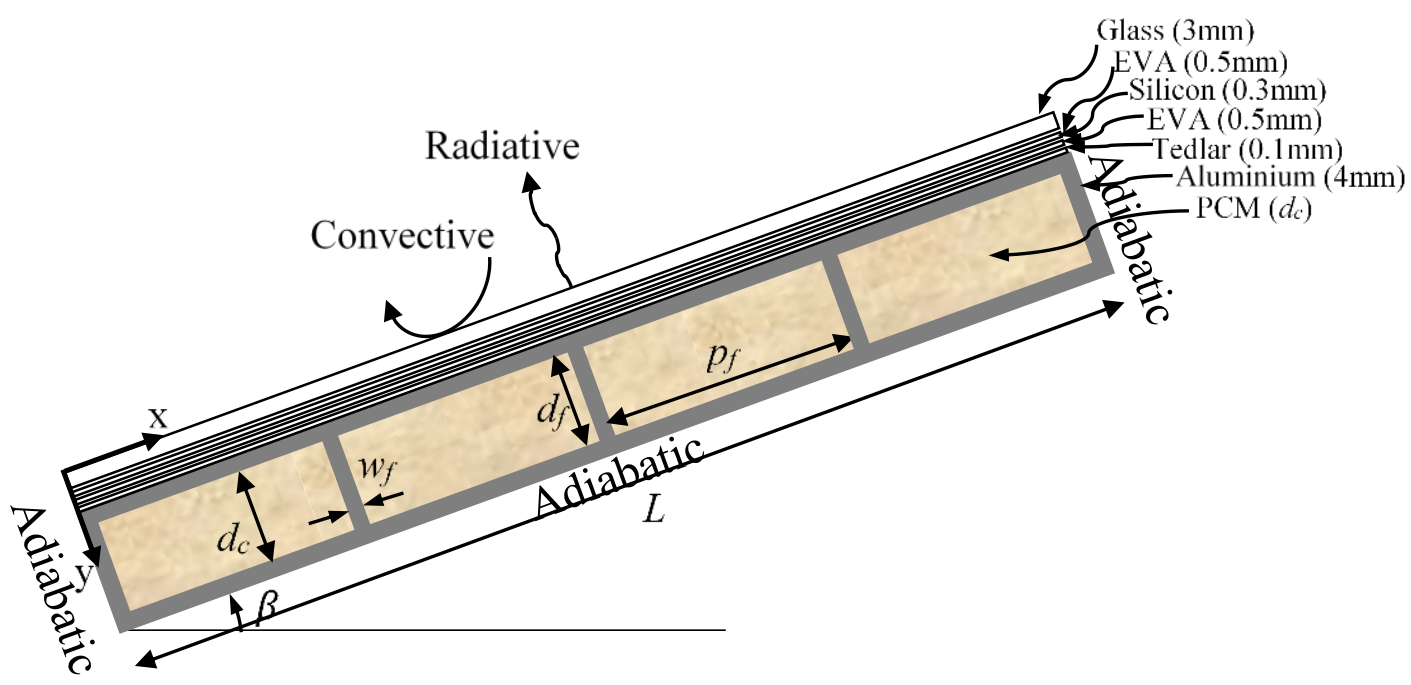

(b) PV-FPCM arrangement

Fig. 1 Arrangements studied in current work

\section{Mathematical Modelling}

The governing equations of the components of the studied arrangements are given in this section. The hypotheses of the model are given below

(i) In terms of space, two dimensional analysis is carried out

(ii) Insulating covering on the PCM confinement leads to adiabatic situation

(iii) Heat generation occurred in silicon

(iv) The fluid flow of liquified material is laminar

\subsection{Glass-Covering}

The governing equation for glass-covering considering the variations in space and time can be written as [22]

$\rho_{g l} C_{p, g l} \frac{\partial T_{g l}(x, y)}{\partial t}=\nabla \cdot\left(k_{g l} \nabla T_{g l}(x, y)\right)$

For solving the above, the following boundary and initial conditions are applied 
$k_{g l} \frac{\partial T_{g l}(x, y)}{\partial y}=h_{c}\left[T_{g l}(x, y)-T_{a}\right]+F_{g l_{-} s u r r} \sigma \varepsilon_{g l}\left[T_{g l}^{4}(x, y)-T_{s u r r}^{4}\right]$ at glass top

$k_{g l} \frac{\partial T_{g l}(x, y)}{\partial x}=0$ at edges of glass

$k_{g l} \frac{\partial T_{g l}(x, y)}{\partial y}=k_{E V A} \frac{\partial T_{E V A 1}(x, y)}{\partial y}$ at glass - EVA interface

$T_{g l}(x, y)=T_{a}$ when $t=0$

Eq. (2) coveys the dissipation of heat from upper-covering to the surroundings. A parameter $(\varepsilon)$ is introduced to evaluate the radiative loss which defines the emittance of the covering for long wavelength radiation. The experimental value for this parameter is taken as $\varepsilon=0.91$. At glass-EVA interface, the rate of energy entering the glass is same as the energy leaving EVA which is conveyed by Eq (4).

\subsection{First EVA-Covering}

The governing equation for the first EVA-covering considering the variations in space and time can be written as [22]

$\rho_{E V A} C_{p, E V A} \frac{\partial T_{E V A 1}(x, y)}{\partial t}=\nabla \cdot\left(k_{E V A} \nabla T_{E V A 1}(x, y)\right)$

For solving the above, the following boundary and initial conditions are applied

$$
\begin{aligned}
& k_{E V A} \frac{\partial T_{E V A 1}(x, y)}{\partial x}=0 \text { at edges of } E V A \\
& k_{E V A} \frac{\partial T_{E V A 1}(x, y)}{\partial y}=k_{s i} \frac{\partial T_{s i}(x, y)}{\partial y} \text { at EVA-silicon interface } \\
& T_{E V A 1}(x, y)=T_{a} \text { when } t=0
\end{aligned}
$$




\subsection{Silicon}

The governing equation for the silicon considering the variations in space and time can be written as [14]

$$
\rho_{s i} C_{p, s i} \frac{\partial T_{s i}(x, y)}{\partial t}=\nabla \cdot\left(k_{s i} \nabla T_{s i}(x, y)\right)+\frac{\left[(\tau \alpha)_{c}-\eta_{o}\left\{1+\beta_{c}\left(T_{P V}-25\right)+\gamma_{c} \ln \left(\frac{S}{1000}\right)\right\}\right] S}{d_{s i}}
$$

First term on right hand side in above equation conveys the rate of heat transfer due to conduction and the second term conveys the rate of heat generation. Heat generation is expressed as the difference between the solar radiation absorbed by PV and the electricity generation which depends on the material of PV cells. To compute the electricity generation, following parameters are introduced for polycrystalline based cells: the efficiency in standard test conditions $\left(\eta_{o}\right), \mathrm{PV}$ temperature $\left(T_{P V}\right)$, temperature coefficient $(\beta c)$, irradiance coefficient $\left(\gamma_{c}\right)$ and irradiance $(S)$. Solar radiation absorbed by PV depends on the transmittance $(\tau)$ of glass covering and absorptance $(\alpha)$ of cells. The experimental values of these parameters are taken as $\beta c=-0.005 \mathrm{~K}^{-1}[23], \gamma_{c}=0.085[23]$ and $(\tau \alpha)_{c}=0.9$ [24].

For solving the above Eq. (10), the following boundary and initial conditions are applied

$$
\begin{aligned}
& k_{s i} \frac{\partial T_{s i}(x, y)}{\partial x}=0 \text { at edges of silicon } \\
& k_{s i} \frac{\partial T_{s i}(x, y)}{\partial y}=k_{E V A} \frac{\partial T_{E V A 2}(x, y)}{\partial y} \text { at silicon }-E V A \text { interface } \\
& T_{s i}(x, y)=T_{a} \text { when } t=0
\end{aligned}
$$




\subsection{Second EVA-Covering}

The governing equation for the second EVA-covering considering the variations in space and time can be written as [22]

$\rho_{E V A} C_{p, E V A} \frac{\partial T_{E V A 2}(x, y)}{\partial t}=\nabla \cdot\left(k_{E V A} \nabla T_{E V A 2}(x, y)\right)$

For solving the above, the following boundary and initial conditions are applied

$$
\begin{aligned}
& k_{E V A} \frac{\partial T_{E V A 2}(x, y)}{\partial x}=0 \text { at edges of EVA } \\
& k_{E V A} \frac{\partial T_{E V A 2}(x, y)}{\partial y}=k_{t e} \frac{\partial T_{t e}(x, y)}{\partial y} \text { at EVA-tedlar interface } \\
& T_{E V A 2}(x, y)=T_{a} \text { when } t=0
\end{aligned}
$$

\subsection{Tedlar}

The governing equation for the tedlar considering the variations in space and time can be written as

$$
\rho_{t e} C_{p, t e} \frac{\partial T_{t e}(x, y)}{\partial t}=\nabla \cdot\left(k_{t e} \nabla T_{t e}(x, y)\right)
$$

For solving the above, the following boundary and initial conditions are applied

$$
k_{t e} \frac{\partial T_{t e}(x, y)}{\partial x}=0 \text { at edges of tedlar }
$$

$k_{t e} \frac{\partial T_{t e}(x, y)}{\partial y}=\left\{\begin{array}{c}h_{c}\left[T_{t e}(x, y)-T_{a}\right]+F_{t e \_s u r r} \sigma \varepsilon_{t e}\left[T_{t e}^{4}(x, y)-T_{s u r r}^{4}\right] \text { at rear PValone } \\ k_{a l} \frac{\partial T_{a l}(x, y)}{\partial y} \text { at tedlar-aluminium interface }\end{array}\right.$

$T_{t e}(x, y)=T_{a}$ when $t=0$ 
Eq. (20) conveys the dissipation of heat from tedlar-covering to the surroundings for PV alone and from tedlar to aluminium for PV-FPCM.

\subsection{Aluminium Confinement}

The governing equations for the aluminium confinement considering the variations in space and time can be written as

$$
\rho_{a l} C_{p, a l} \frac{\partial T_{a l}(x, y)}{\partial t}=\nabla \cdot\left(k_{a l} \nabla T_{a l}(x, y)\right)
$$

For solving the above, the following boundary and initial conditions are applied

$k_{a l} \frac{\partial T_{a l}(x, y)}{\partial x}=0$ at edges of aluminium confinement

$k_{a l} \frac{\partial T_{a l}(x, y)}{\partial y}=k_{P} \frac{\partial T_{P}(x, y)}{\partial y}$ at aluminium - PCM interface along length

$k_{a l} \frac{\partial T_{a l}(x, y)}{\partial x}=k_{P} \frac{\partial T_{P}(x, y)}{\partial x}$ at aluminium - PCM interface along depth

$k_{a l} \frac{\partial T_{a l}(x, y)}{\partial y}=0$ at rear of aluminium confinement

$T_{a l}(x, y)=T_{a}$ when $t=0$

\subsection{PCM}

The governing equations for the PCM considering the variations in space and time are written as [16]

$$
\begin{aligned}
& \rho_{P} C_{p} \frac{\partial T_{P}(x, y)}{\partial t}=\nabla \cdot\left(k_{P} \nabla T_{P}(x, y)\right)-\rho_{P} C_{p, P}\left(\vec{v} . \nabla T_{P}(x, y)\right) \\
& \rho_{P} \frac{\partial v_{x}}{\partial t}+\rho_{P} v_{x} \frac{\partial v_{x}}{\partial x}+\rho_{P} v_{y} \frac{\partial v_{x}}{\partial y}=-\frac{\partial p}{\partial x}+\mu_{P, l} \nabla^{2} \vec{v}+\rho_{P, l} g_{x}\left[1-\beta_{P}\left(T_{P}(x, y)-T_{m}\right)\right]-F_{x}
\end{aligned}
$$


$\rho_{P} \frac{\partial v_{y}}{\partial t}+\rho_{P} v_{x} \frac{\partial v_{y}}{\partial x}+\rho_{P} v_{y} \frac{\partial v_{y}}{\partial y}=-\frac{\partial p}{\partial y}+\mu_{P, l} \nabla^{2} \vec{v}+\rho_{P, l} g_{y}\left[1-\beta_{P}\left(T_{P}(x, y)-T_{m}\right)\right]-F_{y}$

$\nabla \cdot \vec{v}=0$

For solving the above, the following boundary and initial conditions are applied

$$
\begin{aligned}
& k_{P} \frac{\partial T_{P}(x, y)}{\partial y}=k_{a l} \frac{\partial T_{a l}(x, y)}{\partial y} \text { for aluminium - PCM interface along length } \\
& k_{P} \frac{\partial T_{P}(x, y)}{\partial x}=k_{a l} \frac{\partial T_{a l}(x, y)}{\partial x} \text { for aluminium - PCM interface along depth } \\
& T_{P}(x, y)=T_{a} \text { when } t=0 \\
& v_{x}=v_{y}=0 \text { for inside surface of PCM confinement } \\
& v_{x}=v_{y}=0 \text { when } t=0
\end{aligned}
$$

In Eqs. (29-30), $\beta_{P}$ is introduced to incorporate the expansion of PCM. Its experimental value is taken as $0.001 \mathrm{~K}^{-1}$. Two parameters for $\mu$ are introduced to incorporate the dynamic viscosity of PCM in liquidus and non-liquidius states. The experimental value for liquidus state is taken as $0.0018 \mathrm{~kg} / \mathrm{m}$-s [16] and for the non-liquidus state, it is $10^{5} \mathrm{~kg} / \mathrm{m}$-s.

The properties of PCM in relation with PCM liquified fraction ' $f$ ' can be articulated as

$$
\begin{aligned}
& C_{p}(T)=C_{p, s}+\left(C_{p, l}-C_{p, s}\right) f(T)+H_{f} D(T) \\
& \rho(T)=\rho_{s}+\left(\rho_{l}-\rho_{s}\right) f(T) \\
& k(T)=k_{s}+\left(k_{l}-k_{s}\right) f(T)
\end{aligned}
$$

To keep the results independent from the number of nodal points, the results have been produced for three different meshes. First mesh consists of twenty-five thousand nodal points. Second and third consist of fifty thousand and hundred thousand nodal points. Outcomes 
convey that the maximum difference in the system-temperature values is $1.5 \mathrm{~K}$ for first and second meshes. For second and third meshes, the maximum difference is $0.2 \mathrm{~K}$ which conveys that there is no need to improve the mesh beyond second mesh. Thus, second mesh is chosen for producing the results.

\section{Experimental Validation}

Measurements had been taken to examine the response of PV-FPCM during operation (Hasan et al. [2]). The arrangement considered for the experiments was a PV panel having dimensions $77.1 \mathrm{~cm} \times 66.5 \mathrm{~cm}$ equipped with $5 \mathrm{~mm}$ thick aluminium confinement filled with coolant having phase change temperature near to $302.8 \mathrm{~K}$. The confinement's length was $70 \mathrm{~cm}$ and depth was $4 \mathrm{~cm}$. Fins were positioned using pitch of $7.5 \mathrm{~cm}$. The arrangement was put under real environment. The PV temperature of the arrangement was recorded.

To examine the accuracy of the presented equations by matching the calculations with measurements, the investigation is performed taking same specifications. The calculated photovoltaic temperature of the arrangement is plotted in contrast to the measured values in Figure 2. The outcomes convey that the dissimilarity between the both is tolerable. 


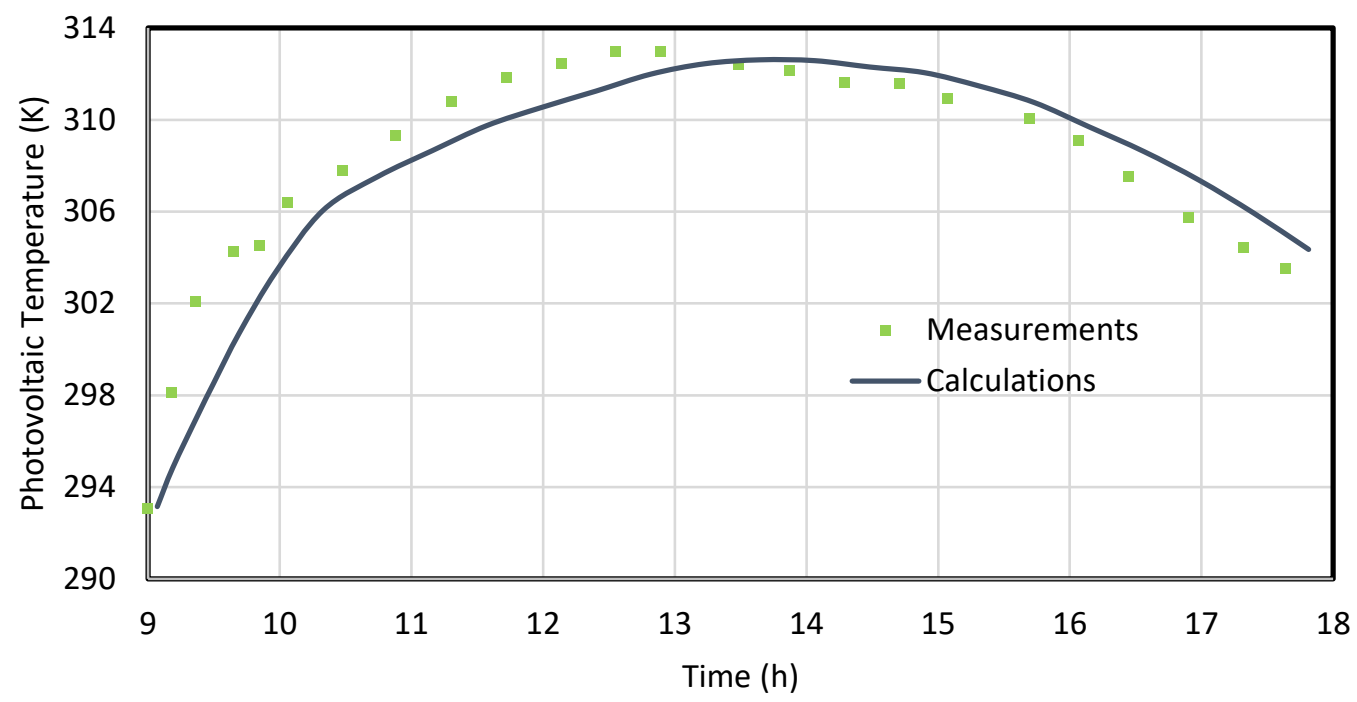

Figure 2 Variation of photovoltaic temperature with time

\section{Results and Discussion}

The PV-FPCM is studied under various azimuths of wind (the angular direction of wind from due south line as shown in Figure 3), its flow rate, temperature of surroundings, phase change temperature and various dimensions of confinements. The power production, efficiency, Power-Voltage curves and the duration of power improvement have been computed and discussed. The arrangements' details are tabulated in Table 1.

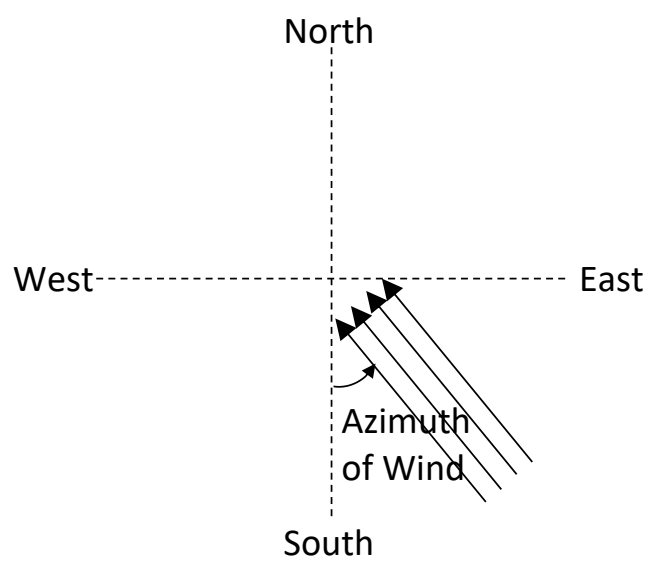

Figure 3 Azimuth of wind 


\subsection{Power Improvement using PV-FPCM}

The power production and efficiency of PV panel, PV-PCM and PV-FPCM are figured. The power improvement, efficiency improvement and Power-Voltage curves are shown in Fig. 4.

The outcomes convey that a power improvement of $12.5 \mathrm{~W} / \mathrm{m}^{2}$ is achieved using PCM confinement. The cause behind this is that the PCM absorbs the waste heat that cools the PV and leads to power improvement. The outcomes also convey that higher improvement of $18.2 \mathrm{~W} / \mathrm{m}^{2}$ is achieved using FPCM. The cause is that the fins increase the amount of heat entering the PCM and improves the PV cooling resulting in power improvement.

It is found that an improvement of $1.7 \%$ in PV efficiency is achieved using PCM confinement. The cause is the lower temperature of PV maintained by phase changing material resulting in efficiency improvement. It is also found that a higher improvement of $2.4 \%$ in PV efficiency is achieved using FPCM. The cause is that the fins provide coolness to the PV resulting in efficiency improvement. 


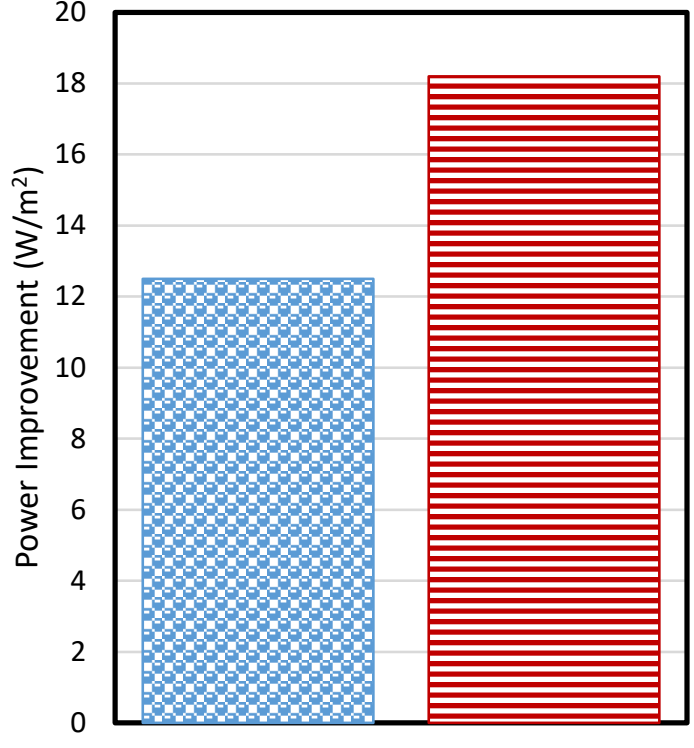

(a) Power Improvement

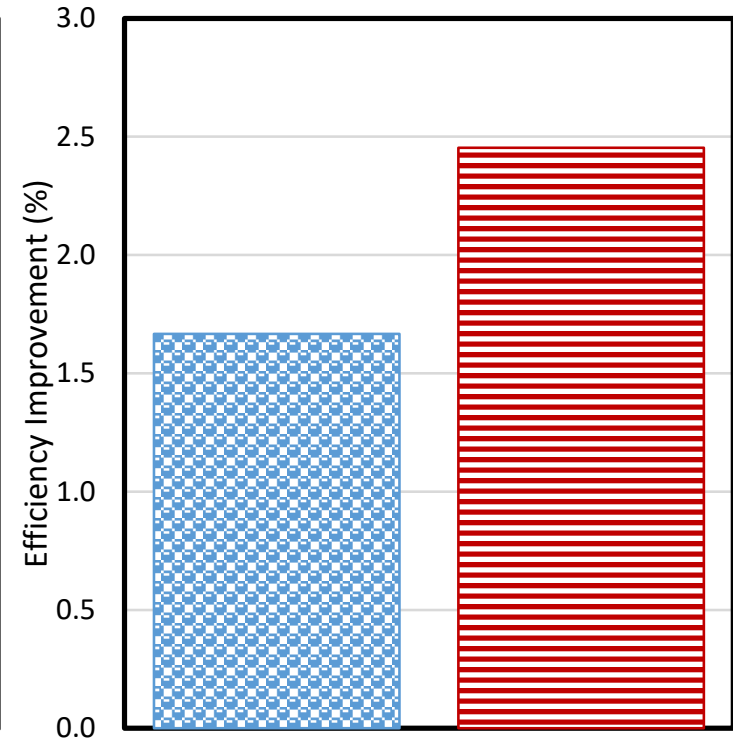

(b) Efficiency Improvement

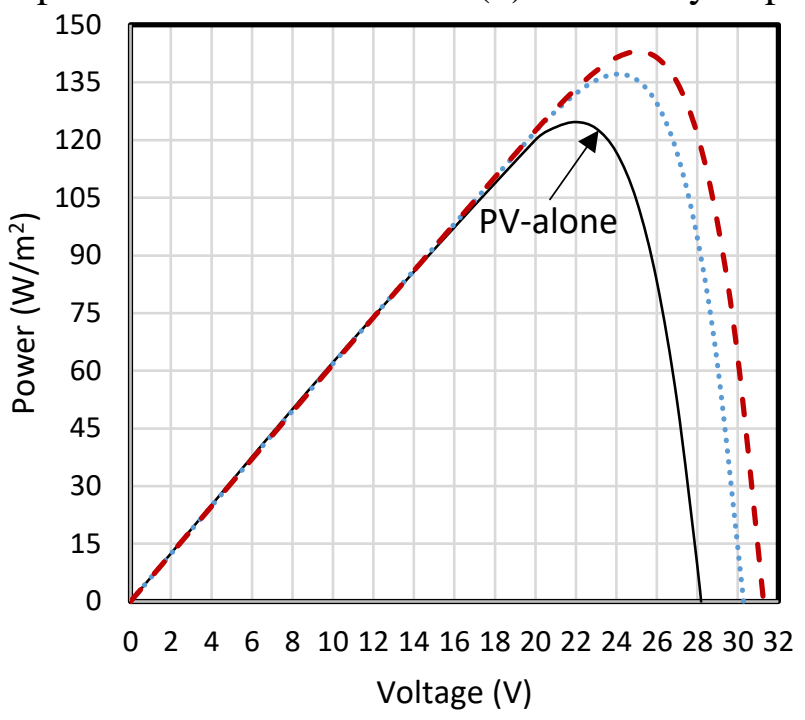

(c) Power-Voltage Curves

Figure 4 Power improvement, efficiency improvement and Power-Voltage Curves (plots with lines are for PV-FPCM and dots are for PV-PCM) keeping $d_{c}=5 \mathrm{~cm}$ and other paramters fixed (Table 1) 


\subsection{Consequence of Flow Rate of Wind}

The duration of power improvement of PV is figured for a number of flow rates of wind, FPCM confinements and depth of confinements and shown in Figure 5.

The outcomes convey that the variation in wind flow rate from $6 \mathrm{~m} / \mathrm{s}$ to $0.2 \mathrm{~m} / \mathrm{s}$ contracts the duration of power improvement from $7.7 \mathrm{~h}$ to $5.7 \mathrm{~h}$ for FPCM confinement (Figure 5a). The cause is described like this: the low wind flow rate cannot remove the PV's warmness powerfully resulting in higher amount of heat entering the FPCM and contracts the phase change process which contracts the duration of power improvement.

The FPCM confinement is also compared against the PCM confinement in Figure 5b. The outcomes convey that the use of FPCM confinement instead of PCM one contracts the duration of power improvement from $7.3 \mathrm{~h}$ to $6.1 \mathrm{~h}$. The cause is that the fins increase the amount of heat entering the PCM and contract the phase change process which contracts the duration of power improvement.

For a number of depths of FPCM confinements (Figure 5a-c), the outcomes convey that the variation in depth from $5 \mathrm{~cm}$ to $3 \mathrm{~cm}$ contracts the duration of power improvement from $6.1 \mathrm{~h}$ to $3.6 \mathrm{~h}$. The cause behind this is the lesser quantity of PCM in the confinement in case of lesser depth which contracts the duration of power improvement. 


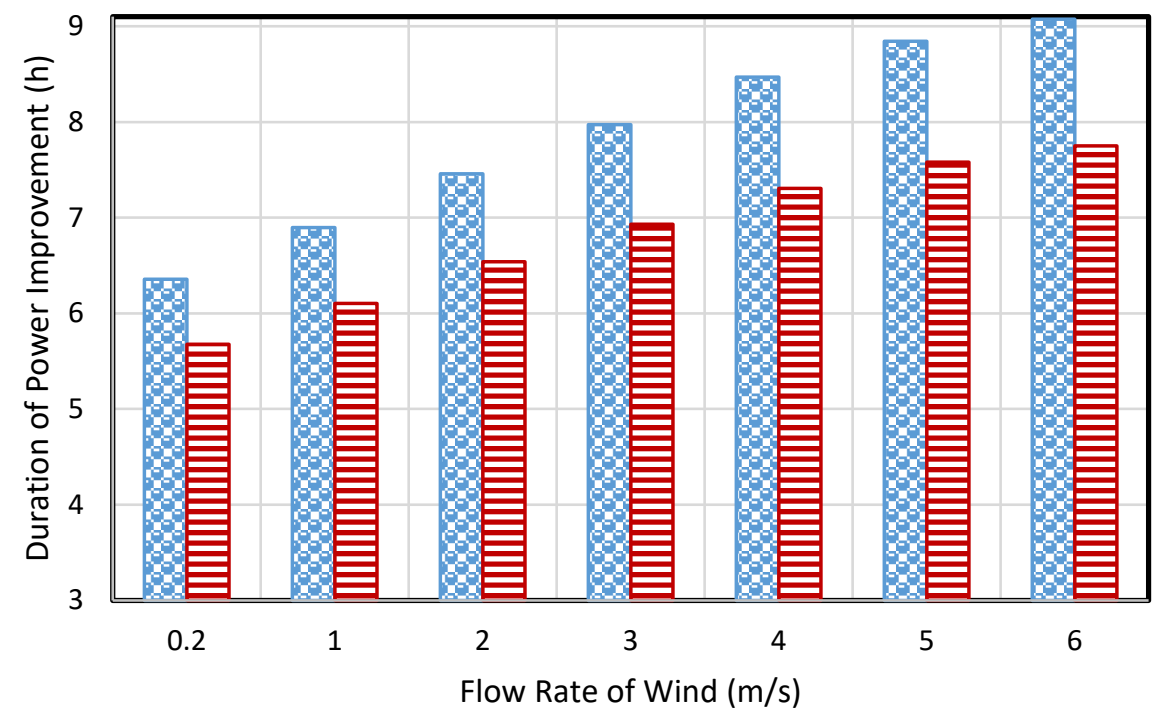

(a)

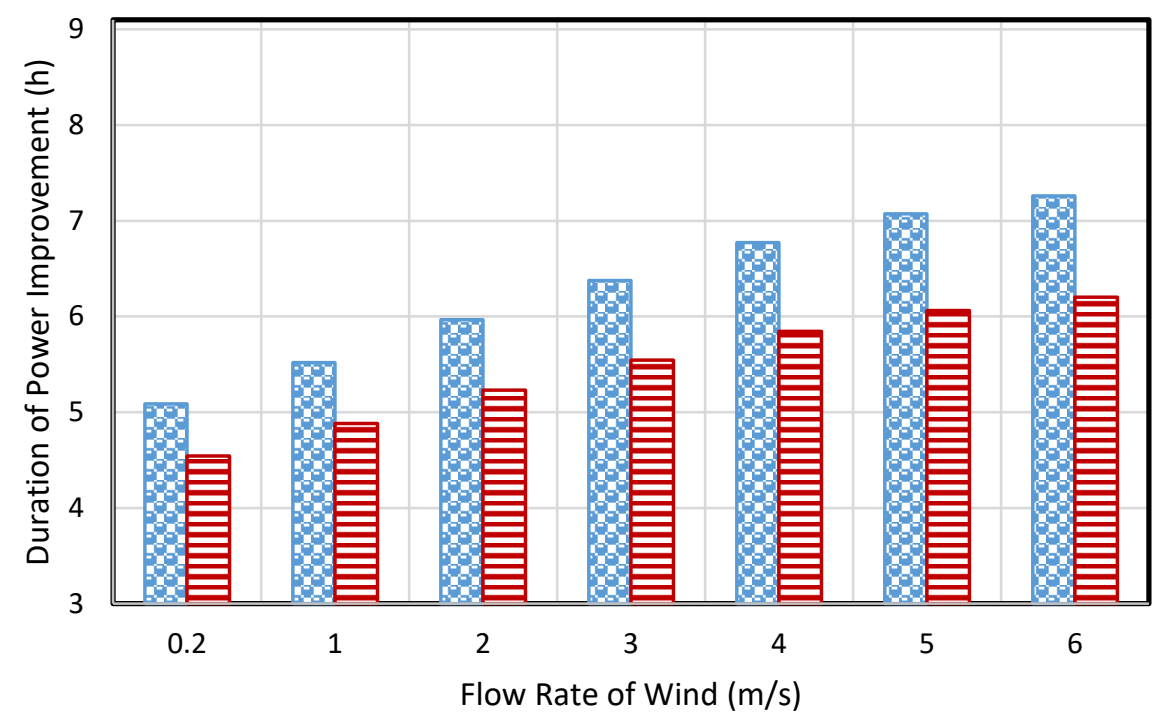

(b)

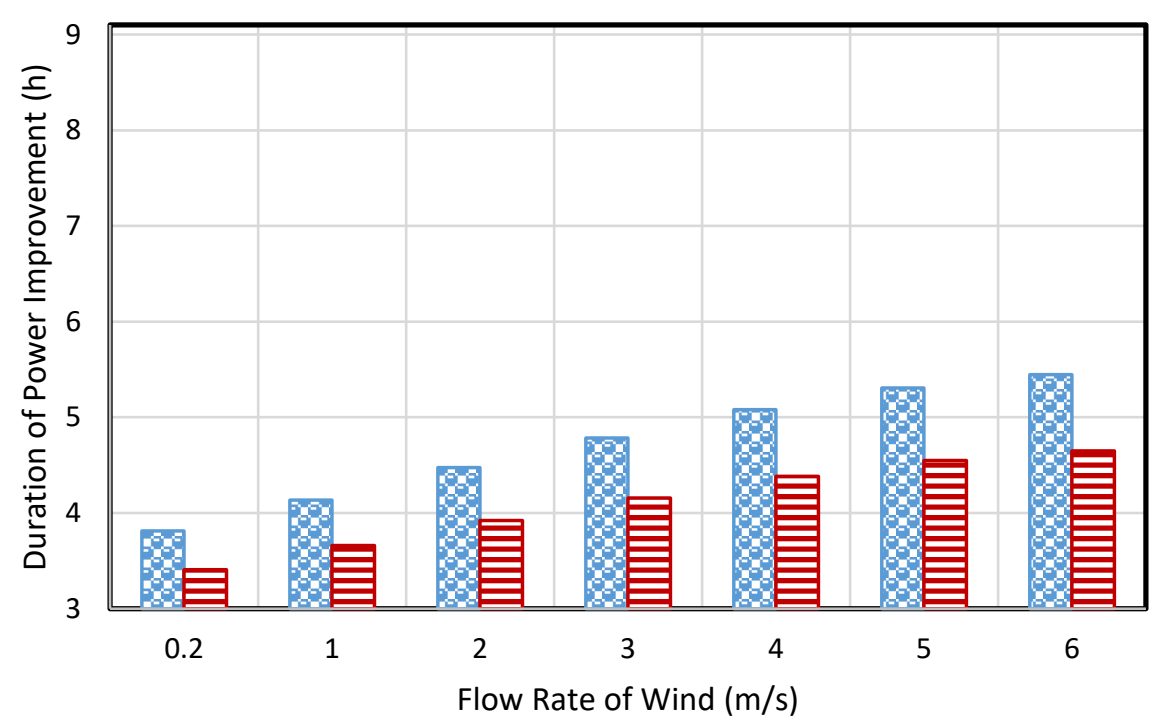

(c)

Figure 5 Duration of power improvement for a number of flow rates of wind \& depth of confinement (plots with lines are for FPCM and dots are for PCM) (a) $d_{c}=5 \mathrm{~cm},(b) d_{c}=4 \mathrm{~cm}$ and $(c) d_{c}=3 \mathrm{~cm}$ keeping other parameters fixed (Table 1) 


\subsection{Consequence of Azimuth of Wind}

The duration of power improvement of PV is figured for a number of azimuths of wind, FPCM confinements and depth of confinements and shown in Figure 6.

The outcomes convey that the variation in azimuth of wind from $75^{\circ}$ to $0^{\circ}$ expands the duration of power improvement from 6.1 to $7.3 \mathrm{~h}$ for FPCM confinement (Figure 6a). The cause is described like this: when wind strikes the PV perpendicularly, it removes the PV's warmness powerfully resulting in lower amount of heat entering the FPCM and expands the phase change process which expands the duration of power improvement.

The FPCM confinement is also compared against the PCM confinement in Figure 6b. The outcomes convey that the use of FPCM confinement instead of PCM one contracts the duration of power improvement from $6.9 \mathrm{~h}$ to $5.8 \mathrm{~h}$. It is because of the earlier mentioned reason of increased amount of heat entering the confinement in case of FPCM which contracts the phase change process and the duration of power improvement.

For a number of depths of FPCM confinements (Figure 6a-c), the outcomes convey that the variation in depth from $3 \mathrm{~cm}$ to $5 \mathrm{~cm}$ expands the duration of power improvement from $4.4 \mathrm{~h}$ to $7.3 \mathrm{~h}$. 


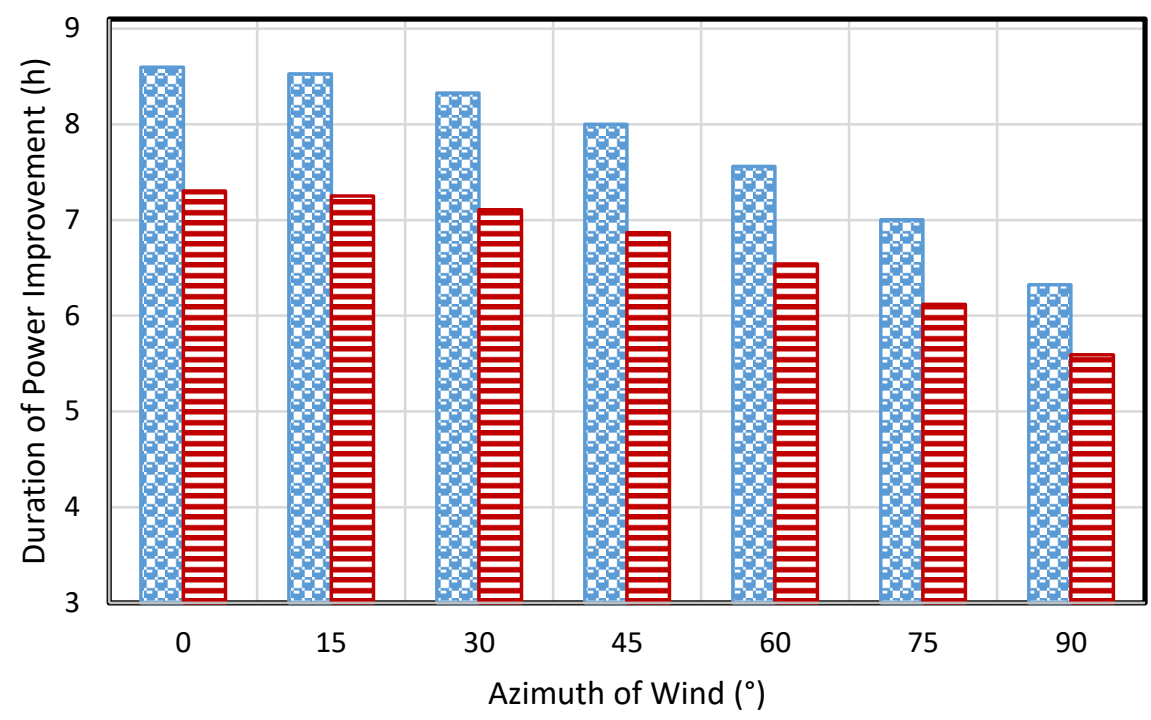

(a)

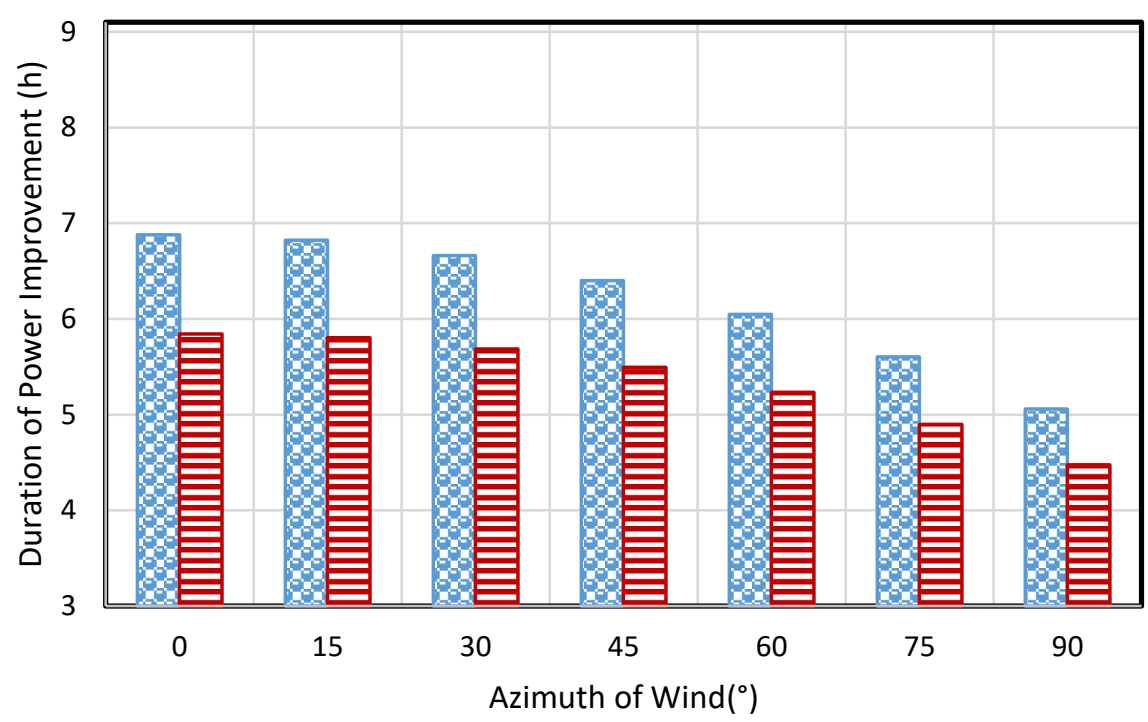

(b)

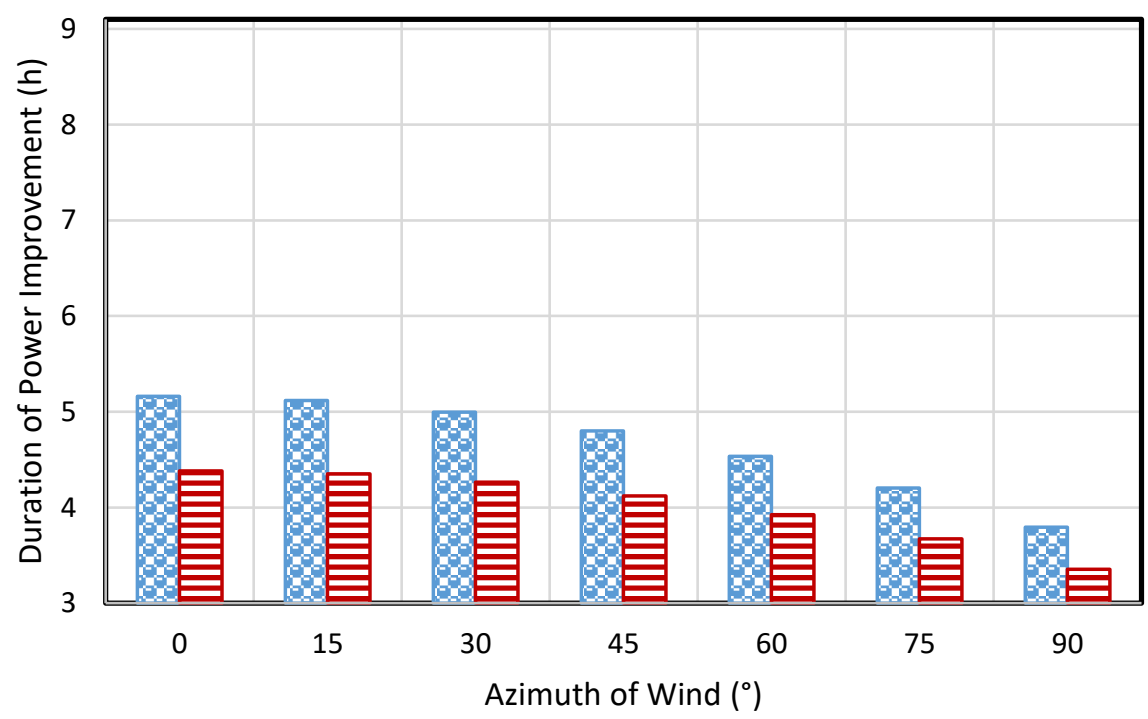

(c)

Figure 6 Duration of power improvement for a number of azimuth of wind and depth of confinement (plots with lines are for FPCM and dots are for PCM) $(a) d_{c}=5 \mathrm{~cm},(b) d_{c}=4 \mathrm{~cm}$ and $(c) d_{c}=3 \mathrm{~cm}$ keeping other parameters fixed (Table 1) 


\subsection{Consequence of Temperature of Surroundings}

The duration of power improvement of PV is figured for a number of temperature of surroundings, FPCM confinements and depth of confinements and shown in Figure 7.

The outcomes convey that the variation in temperature of surroundings from $289 \mathrm{~K}$ to $299 \mathrm{~K}$ leads to change in the duration of power improvement from $10.1 \mathrm{~h}$ to $6.2 \mathrm{~h}$ for $5 \mathrm{~cm}$ deep FPCM confinement (Figure 7a). Thus, the increment in temperature of surroundings contracts the duration of power improvement. The cause is that the high temperature of surroundings leads to large amount of heat entering the FPCM which contracts the phase change process and contracts the duration of power improvement.

The FPCM confinement is also compared against the PCM confinement in Figure $7 \mathrm{~b}$ for $4 \mathrm{~cm}$ deep confinement. The outcomes convey that the use of FPCM confinement instead of PCM one contracts the duration of power improvement from 9.9h to $8.1 \mathrm{~h}$.

For a number of depths of FPCM confinements (Figure 7a-c), the outcomes convey that the variation in depth from $5 \mathrm{~cm}$ to $3 \mathrm{~cm}$ leads to change in the duration of power improvement from $10.2 \mathrm{~h}$ to $6.1 \mathrm{~h}$. Thus, the decrement in depth of confinement contracts the duration of power improvement. 


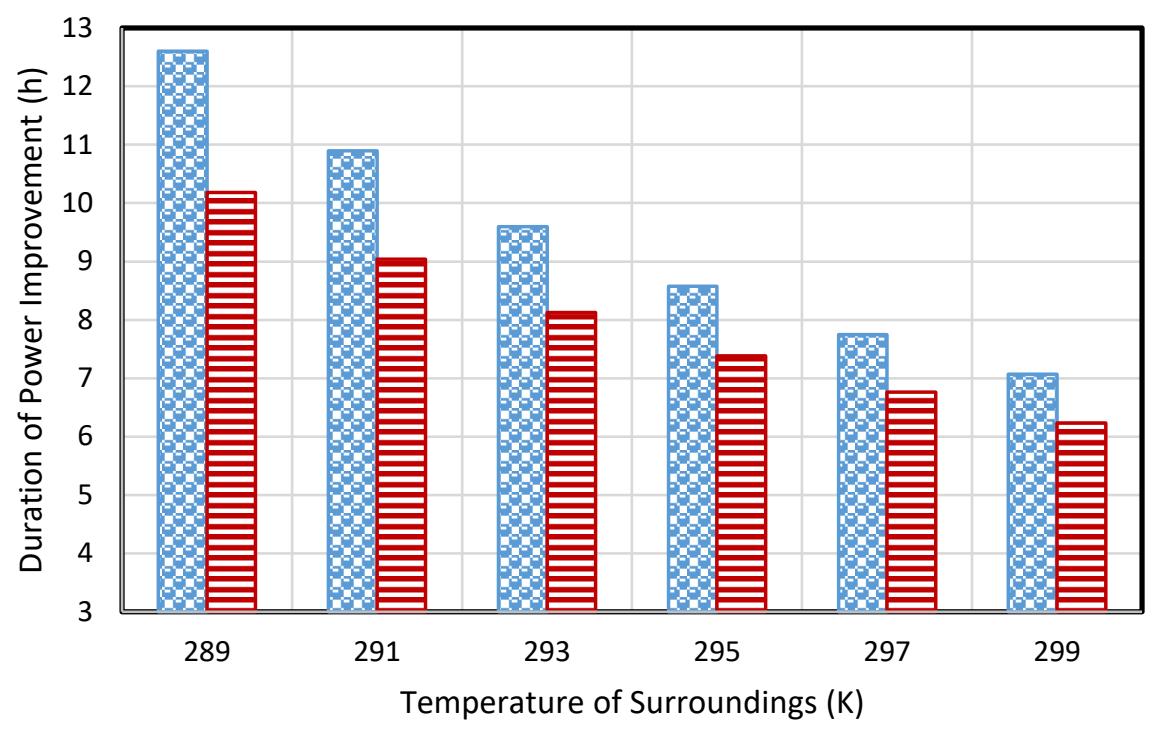

(a)

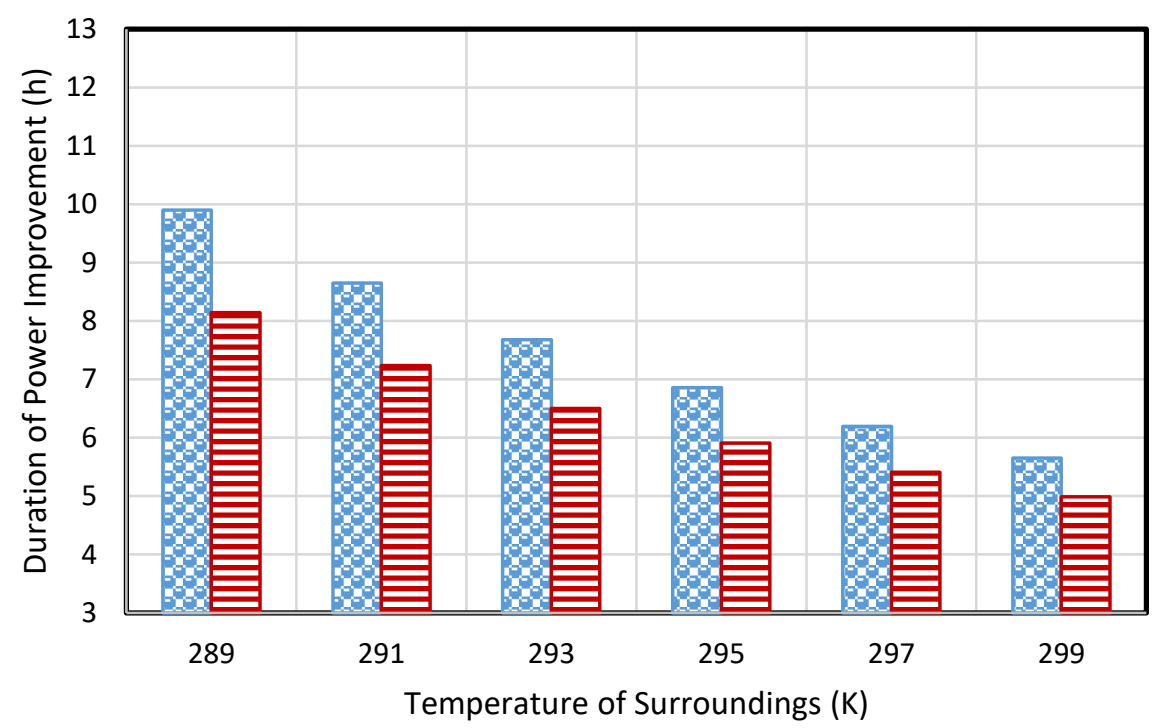

(b)

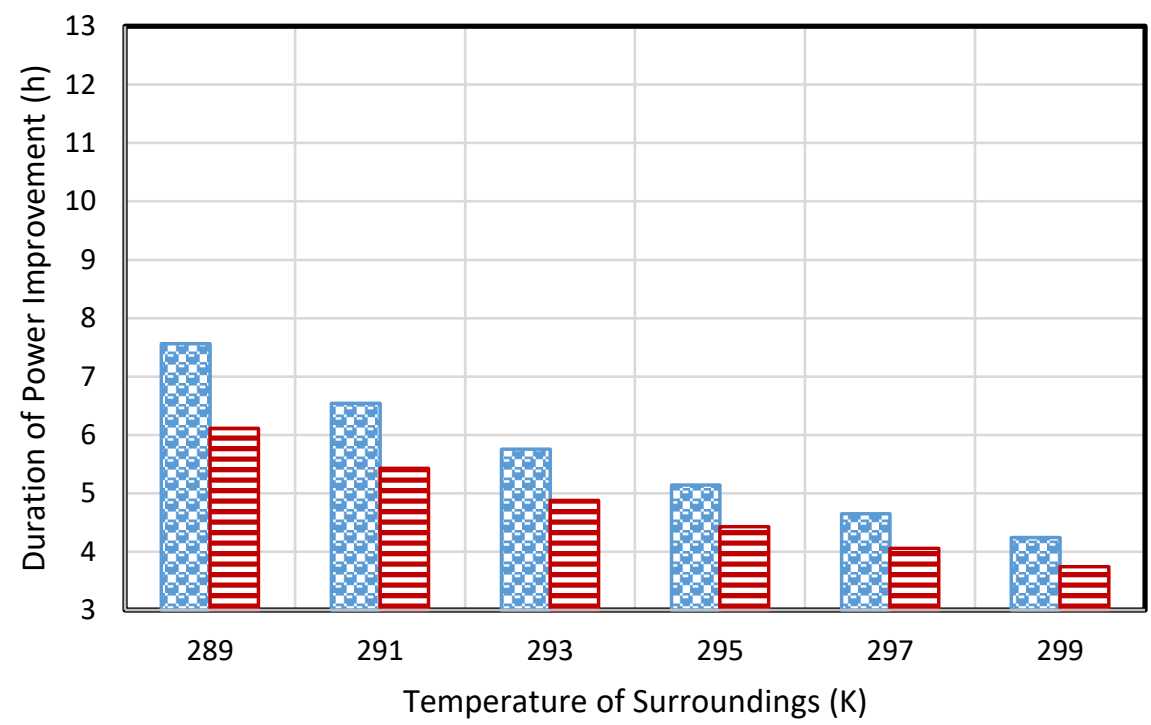

(c)

Figure 7 Duration of power improvement for a number of temperature of surroundings and depth of confinement (plots with lines are for FPCM and dots are for PCM) $(a) d_{c}=5 \mathrm{~cm},(b) d_{c}=4 \mathrm{~cm}$ and (c) $d_{c}=3 \mathrm{~cm}$ keeping other parameters fixed (Table 1) 


\subsection{Consequence of Phase Change Temperature}

The duration of power improvement of PV is figured for a number of phase change temperatures, FPCM confinements and depth of confinements and shown in Figure 8.

The outcomes convey that the variation in phase change temperature from $291 \mathrm{~K}$ to $301 \mathrm{~K}$ leads to change in the duration of power improvement from $5.8 \mathrm{~h}$ to $10.0 \mathrm{~h}$ for $5 \mathrm{~cm}$ deep FPCM confinement (Figure 8a). Thus, the decrement in phase change temperature contracts the duration of power improvement. The cause is described like this: the low phase change temperature assists the photovoltaic to work at low temperature which lowers down the thermal loss to ambient resulting in higher amount of heat entering the PCM and contracts the phase change process which contracts the duration of power improvement.

The FPCM confinement is compared against the PCM confinement in Figure $8 \mathrm{~b}$ for $4 \mathrm{~cm}$ deep confinement. The outcomes convey that the use of FPCM confinement instead of PCM one contracts the duration of power improvement from 9.8h to 8.0h.

For a number of depths of FPCM confinements (Figure 8a-c), the outcomes convey that the variation in depth from $5 \mathrm{~cm}$ to $3 \mathrm{~cm}$ leads to change in the duration of power improvement from $10.0 \mathrm{~h}$ to $6.0 \mathrm{~h}$. Thus, the decrement in depth of confinement contracts the duration of power improvement. It is because of the earlier mentioned reason of lesser quantity of PCM that can improve the PV power for shorter duration. 


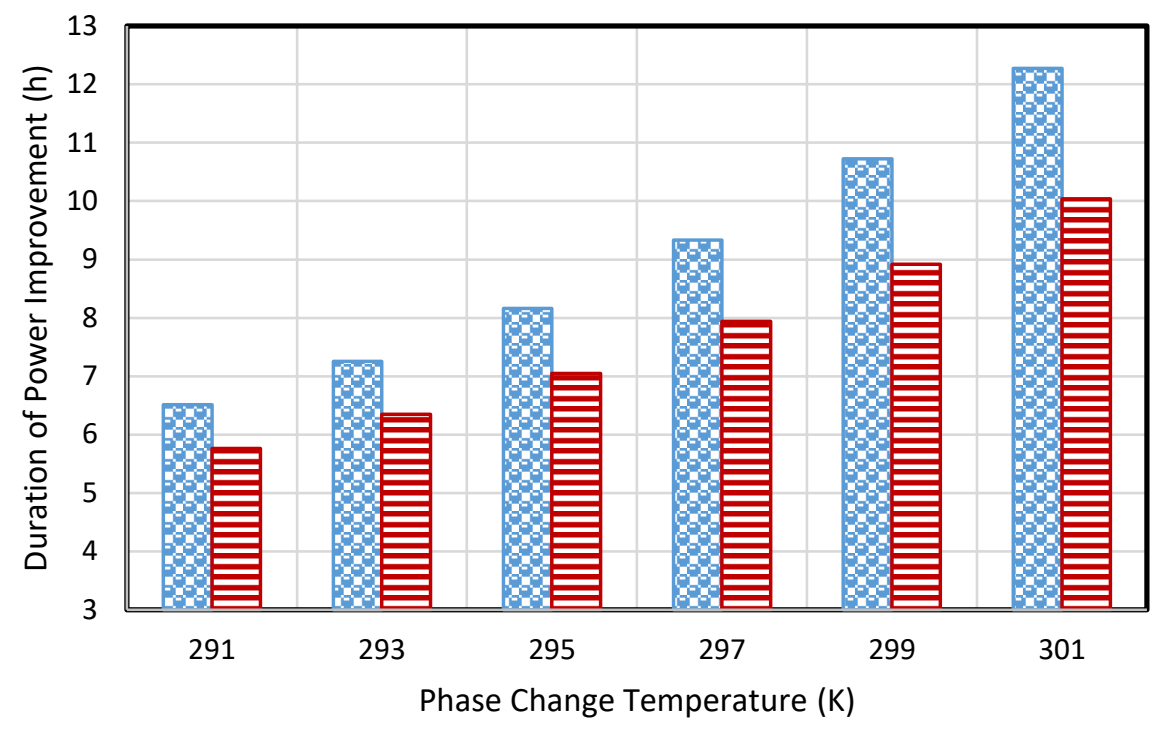

(a)

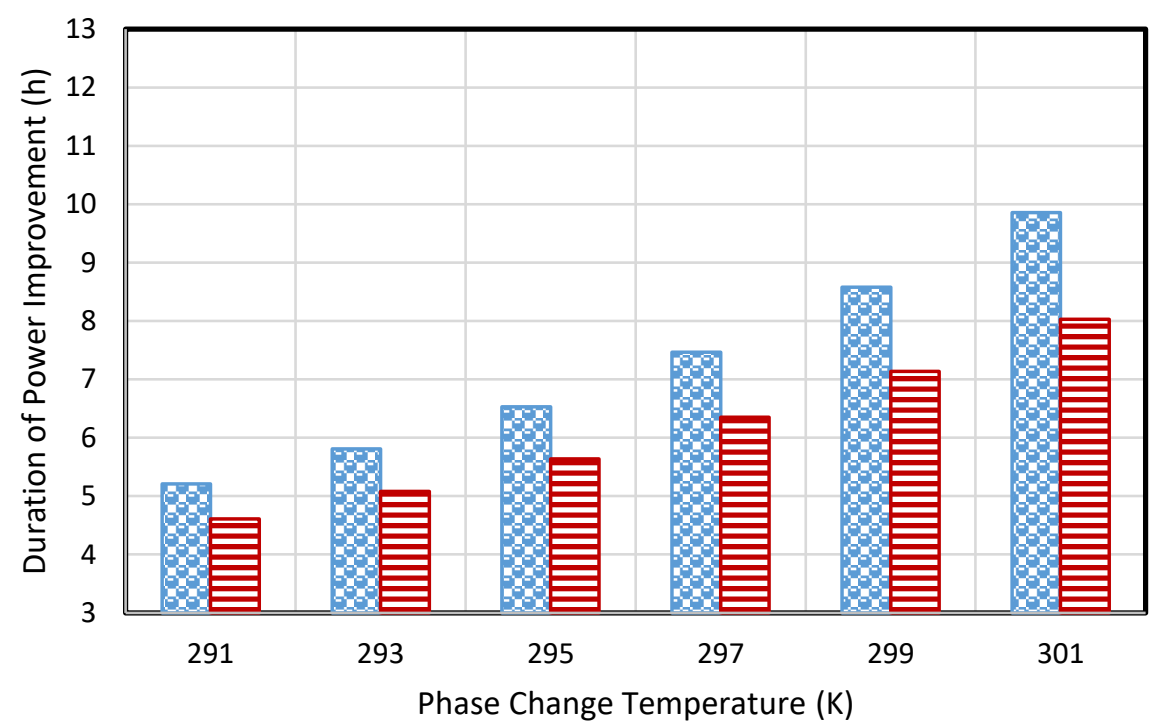

(b)

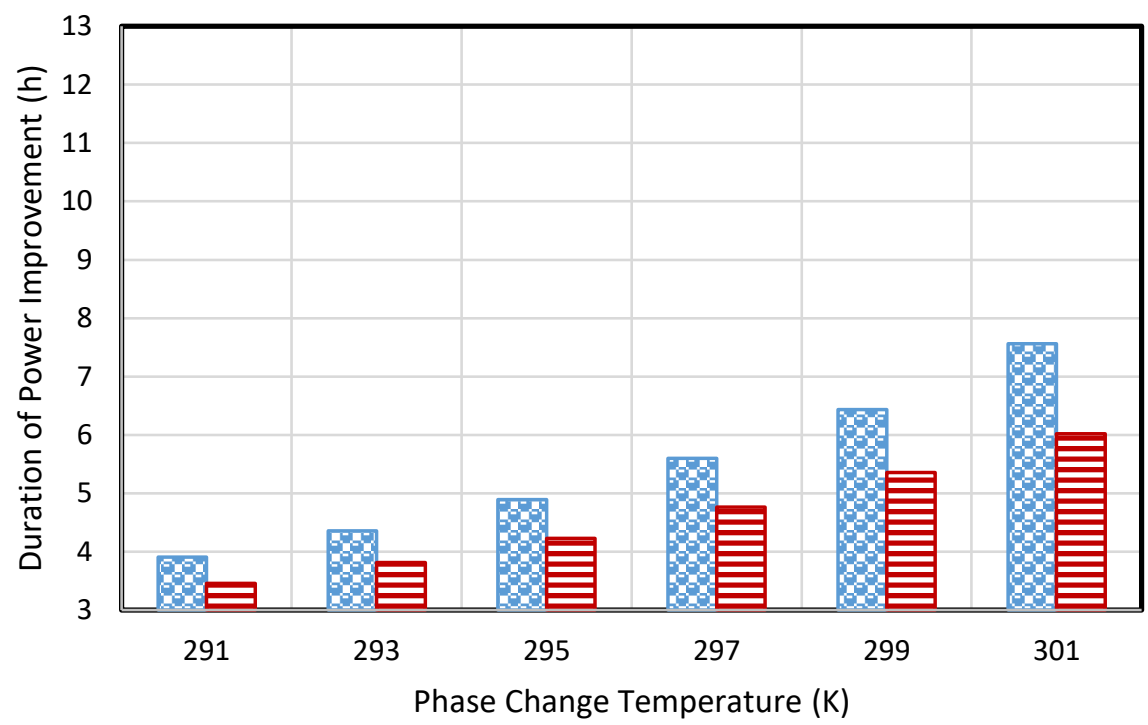

(c)

Figure 8 Duration of power improvement for a number of phase change temperature and depth of confinement (plots with lines are for FPCM and dots are for PCM) $(a) d_{c}=5 \mathrm{~cm},(b) d_{c}=4 \mathrm{~cm}$ and $(c) d_{c}$ $=3 \mathrm{~cm}$ keeping other parameters fixed (Table 1) 


\section{Conclusions}

The study presents a mathematical model for PV-FPCM system and analyses the system under various azimuths of wind, its flow rates, temperature of surroundings, phase change temperature and dimensions of FPCM-confinement. The improvement in power production, improvement in efficiency, Power-Voltage Curves and duration of power improvement have been computed. Outcomes convey that

(i) Variation in azimuth of wind from $75^{\circ}$ to $0^{\circ}$ expands the duration of power improvement from 6.1 to $7.3 \mathrm{~h}$.

(ii) Decrement in wind flow rate from 6 to $0.2 \mathrm{~m} / \mathrm{s}$ contracts the duration of power improvement from 7.7 to $5.7 \mathrm{~h}$.

(iii) Increment in temperature of surroundings 289 to $299 \mathrm{~K}$ contracts the duration of improvement from 10.1 to $6.2 \mathrm{~h}$.

(iv) Variation in phase change temperature from $291 \mathrm{~K}$ to $301 \mathrm{~K}$ expands the duration of power improvement from 5.8 to $10.0 \mathrm{~h}$. 


\section{Acknowledgement}

The University of Portsmouth has received funding from the Interreg 2 Seas programme 2014-2020 co-funded by the European Regional Development Fund under subsidy contract No 2S04-004 (SOLARISE).

\section{References}

[1] Baygi S.R.M., Sadrameli S.M., 2018. Thermal management of PV using polyethylene glycol 1000 (PEG1000) as a PCM. Thermal Science and Engineering Progress 5, 405-411.

[2] Hasan A., McCormack S.J., Huang M.J., Sarwar J., Norton B., 2015. Increased photovoltaic performance through temperature regulation by phase change materials: Materials comparison in different climates. Solar Energy 115, 264-276.

[3] Huang M.J., Eames P.C., Norton B., 2006. Phase change materials for limiting temperature rise in building integrated photovoltaics. Solar Energy 80, 1121-1130.

[4] Indartono Y.S., Suwono A., Pratama F.Y., 2014. Improving PV performance by using yellow petroleum jelly as PCM. International Journal of Low-Carbon Technologies 0, 1-5.

[5] Hasan A., McCormack S.J., Huang M.J., Norton B., 2010. Evaluation of phase change materials for thermal regulation enhancement of building integrated photovoltaics. Solar Energy 84, 1601-1612.

[6] Kamkari B., Groulx D., 2018. Experimental investigation of melting behaviour of phase change material in finned rectangular enclosures under different inclination angles. Experimental Thermal and Fluid Science 97, 94-108.

[7] Sharma S., Tahir A., Reddy K.S., Mallick T.K., 2016. Performance enhancement of a BICPV using PCM. Solar Energy Materials \& Solar Cells 149, 29-39.

[8] Al-Waeli A.H.A., Sopian K., Chaichan M.T., Kazem H.A., Ibrahim A., Mat S., Ruslan M.H., 2017. Evaluation of the nanofluid and nano-PCM based PVT system: An experimental study. Energy Conversion and Management 151, 693-708. 
[9] Su Y., Zhang Y., Shu L., 2018. Experimental study of using phase change material cooling in a solar tracking concentrated photovoltaic-thermal system. Solar Energy 159, $777-785$.

[10] Hossain M.S., Pandey A.K., Selvaraj J., Rahim N.A., Islam M.M., Tyagi V.V., 2019. Two side serpentine flow based PVT-PCM system: Energy, exergy and economic analysis Renewable Energy 136, 1320-1336.

[11] Maatallah T., Zachariah R., Al-Amri F.G., 2019. Exergo-economic analysis of a serpentine flow type water based PVT system with PCM (PVT-PCM/water). Solar Energy 193, 195-204.

[12] Brano V.L., Ciulla G., Piacentino A., Cardona F., 2014. Finite difference thermal model of a latent heat storage system coupled with a photovoltaic device: Description and experimental validation. Renewable Energy 68, 181-193.

[13] Ciulla G., Brano V.L., Cellura M., Franzitta V., Milone D., 2012. A finite difference model of a PV-PCM system. Energy Procedia 30, 198-206.

[14] Kant K., Shukla A., Sharma A., Biwole P.H., 2016. Heat transfer studies of photovoltaic panel coupled with phase change material. Solar Energy 140, 151-161.

[15] Kibria M.A., Saidur R., Al-Sulaiman F.A., Aziz M.M.A., 2016. Development of a thermal model for a hybrid photovoltaic module and phase change materials storage integrated in buildings. Solar Energy 124, 114-123.

[16] Biwole P.H., Eclache P., Kuznik F., 2013. Phase-change materials to improve solar panel's performance. Energy and Buildings 62, 59-67.

[17] Biwole P.H., Groulx D., Souayfane F., Chiu T., 2018. Influence of fin size and distribution on solid-liquid phase change in a rectangular enclosure. International Journal of Thermal Sciences 124, 433-446.

[18] Park J., Kim T., Leigh S.B., 2014. Application of a phase-change material to improve the electrical performance of vertical-building-added photovoltaics considering the annual weather conditions. Solar Energy 105, 561-674. 
[19] Atkin P., Farid M.M., 2015. Improving the efficiency of photovoltaic cells using PCM infused graphite and aluminium fins. Solar Energy 114, 217-228.

[20] Huang M.J., Eames P.C., Norton B., 2004. International Journal of Heat and Mass Transfer 47, 2715-2733.

[21] Emam M., Ahmed A., 2018. Cooling CPV using various configurations of PCM heat sinks. Energy Conversion and Management 158, 298-314.

[22] Jones A.D., Underwood C.P., 2001. A thermal model for PV, Solar Energy 70 349-359.

[23] Skoplaki E., Palyvos J.A. 2009. On the temperature dependence of PV module electrical performance: A review of efficiency/power correlations. Solar Energy 83, 614-624.

[24] Armstrong S., Hurley W.G., 2010. A thermal model for PV panels under varying atmospheric conditions, Applied Thermal Engineering 30 1488-1495. 
Table 1 Specifications of the arrangement

\begin{tabular}{|c|c|c|c|c|c|c|c|c|c|}
\hline & Aluminium & Ambient & $\overline{\text { EVA }}$ & Glass & $\begin{array}{l}\text { PCM } \\
\text { (liquidus) }\end{array}$ & \begin{tabular}{|l|} 
PCM \\
(solidus)
\end{tabular} & Silicon & Tedlar & Fin \\
\hline$C_{p}\left(\mathrm{~kJ} \mathrm{~kg}^{-1} \mathrm{~K}^{-1}\right)$ & 0.9 & - & 2.1 & 0.5 & 2.4 & 1.8 & 0.7 & 1.3 & 0.9 \\
\hline$d(\mathrm{~mm})$ & 4 & - & 0.5 & 3 & $30-50$ & - & 0.3 & 0.1 & $d_{c}$ \\
\hline$f_{w}\left(\mathrm{~m} \mathrm{~s}^{-1}\right)$ & - & 4 & - & - & - & - & - & - & - \\
\hline$h_{c}\left(\mathrm{Wm}^{-2} \mathrm{~K}^{-1}\right)$ & - & - & - & $4-13$ & - & - & - & - & - \\
\hline$H_{f}\left(\mathrm{~kJ} \mathrm{~kg}^{-1}\right)$ & - & - & - & - & 232 & & - & - & - \\
\hline$k\left(\mathrm{~W} \mathrm{~m}^{-1} \mathrm{~K}^{-1}\right)$ & 211 & - & 0.35 & 1.8 & 0.18 & 0.19 & 148 & 0.2 & 211 \\
\hline$L(\mathrm{~m})$ & 1 & - & 1 & 1 & 1 & 1 & 1 & 1 & - \\
\hline$p_{f}(\mathrm{~cm})$ & - & - & - & - & - & - & - & - & 25 \\
\hline$S\left(\mathrm{~kW} \mathrm{~m}^{-2}\right)$ & - & 0.75 & - & - & - & - & - & - & - \\
\hline$T_{a}(\mathrm{~K})$ & - & 293 & - & - & - & - & - & - & - \\
\hline$T_{m}(\mathrm{~K})$ & - & - & - & - & 298 & - & - & - & - \\
\hline$w_{f}(\mathrm{~mm})$ & - & - & - & - & - & - & - & - & 2 \\
\hline$\beta$ & $45^{\circ}$ & - & $45^{\circ}$ & $45^{\circ}$ & $45^{\circ}$ & $45^{\circ}$ & $45^{\circ}$ & $45^{\circ}$ & $45^{\circ}$ \\
\hline$\beta_{c}\left(\mathrm{~K}^{-1}\right)$ & - & - & - & - & - & - & -0.005 & - & - \\
\hline$\beta_{P}\left(\mathrm{~K}^{-1}\right)$ & - & - & - & - & 0.001 & - & - & - & - \\
\hline$\gamma_{c}$ & - & - & - & - & - & - & 0.085 & - & - \\
\hline$\varepsilon$ & - & - & - & 0.85 & - & - & - & 0.91 & - \\
\hline$\mu\left(\mathrm{kg} \mathrm{m}^{-1} \mathrm{~s}^{-1}\right)$ & - & - & - & - & 0.0018 & $10^{5}$ & - & - & - \\
\hline$\rho\left(\mathrm{kg} \mathrm{m}^{-3}\right)$ & 2675 & - & 960 & 3000 & 749 & 785 & 2330 & 1200 & 2675 \\
\hline$(\tau \alpha)_{c}$ & - & - & - & 0.9 & - & - & - & - & - \\
\hline
\end{tabular}

